\title{
Hypermethylation of the DPYD promoter region is not a major predictor of severe toxicity in 5-fluorouracil based chemotherapy Ursula Amstutz ${ }^{1}$, Simone Farese ${ }^{2}$, Stefan Aebi ${ }^{2}$ and Carlo R Largiadèr*1
}

\author{
Address: ${ }^{1}$ Institute of Clinical Chemistry, Inselspital, Bern University Hospital, and University of Bern, CH-3010 Bern, Switzerland and \\ 2Department of Medical Oncology, Inselspital, Bern University Hospital, and University of Bern, CH-3010 Bern, Switzerland \\ Email: Ursula Amstutz - ursula.amstutz@insel.ch; Simone Farese - simone.farese@insel.ch; Stefan Aebi - stefan.aebi@insel.ch; \\ Carlo R Largiadèr* - carlo.largiader@insel.ch \\ * Corresponding author
}

Published: 20 October 2008

Journal of Experimental \& Clinical Cancer Research 2008, 27:54 doi:10.1 186/1756-9966-27-54

This article is available from: http://www.jeccr.com/content/27///54

(C) 2008 Amstutz et al; licensee BioMed Central Ltd.

This is an Open Access article distributed under the terms of the Creative Commons Attribution License (http://creativecommons.org/licenses/by/2.0), which permits unrestricted use, distribution, and reproduction in any medium, provided the original work is properly cited.
Received: 22 July 2008

Accepted: 20 October 2008

\begin{abstract}
Background : The activity of dihydropyrimidine dehydrogenase (DPD), the key enzyme of pyrimidine catabolism, is thought to be an important determinant for the occurrence of severe toxic reactions to 5-fluorouracil (5-FU), which is one of the most commonly prescribed chemotherapeutic agents for the treatment of solid cancers. Genetic variation in the DPD gene (DPYD) has been proposed as a main factor for variation in DPD activity in the population. However, only a small proportion of severe toxicities in 5-FU based chemotherapy can be explained with such rare deleterious DPYD mutations resulting in severe enzyme deficiencies. Recently, hypermethylation of the DPYD promoter region has been proposed as an alternative mechanism for DPD deficiency and thus as a major cause of severe 5-FU toxicity.
\end{abstract}

Methods : Here, the prognostic significance of this epigenetic marker with respect to severe 5FU toxicity was assessed in 27 cancer patients receiving 5-FU based chemotherapy, including 17 patients experiencing severe toxic side effects following drug administration, none of which were carriers of a known deleterious DPYD mutation, and ten control patients. The methylation status of the DPYD promoter region in peripheral blood mononuclear cells was evaluated by analysing for each patient between 19 and 30 different clones of a PCR-amplified 209 base pair fragment of the bisulfite-modified DPYD promoter region. The fragments were sequenced to detect bisulfiteinduced, methylation-dependent sequence differences.

Results : No evidence of DPYD promoter methylation was observed in any of the investigated patient samples, whereas in a control experiment, as little as 10\% methylated genomic DNA could be detected.

Conclusion : Our results indicate that DYPD promoter hypermethylation is not of major importance as a prognostic factor for severe toxicity in 5-FU based chemotherapy.

\section{Background}

5-fluorouracil (5-FU) has been one of the most commonly prescribed chemotherapeutic agents in the treatment of various types of cancer for over 40 years with approximately two million patients treated worldwide each year [1]. However, $10-30 \%$ of patients receiving the drug develop a severe to life-threatening toxic reaction [2]. 5 -FU is a prodrug, thus requiring intracellular conversion 
into cytotoxic metabolites for anti-tumour effects to take place and giving 5-FU metabolising enzymes a crucial role in determining the effect of the drug [1]. Since about $85 \%$ of the administered dose of 5-FU are usually rapidly eliminated, the catabolic pathway, and its key enzyme dihydropyrimidine dehydrogenase (DPD), are particularly important in determining a patient's response to 5-FU [3].

DPD activity is highly variable in the population, with an estimated proportion of 3-5\% of individuals showing low or deficient DPD activity [4], which is thought to result in an increased half-life of 5-FU and therefore an increased risk of toxicity [1]. Part of this variability is explained by genetic variation in the DPD gene (DPYD), where over 40 polymorphisms have been described so far. Several of these gene variants have been associated with reduced enzyme activity and severe toxic side effects to 5FU [1,5-9], the most prominent being a point mutation in the splice site of intron 14 (IVS14+1G>A) resulting in the deletion of exon 14 and thus a non-functional enzyme $[10,11]$. However, the clinical consequences of this and other mutations in the DPD gene remain unclear, and a large proportion of the observed variation in DPD activity is still unexplained. Recently, partial methylation of the DPYD promoter region has been suggested as an alternative mechanism for DPD deficiency and thus also as a basis for 5-FU toxicity [12]. More specifically, in this study, patients and healthy volunteers with low DPD activity displayed a partially methylated DPYD promoter region, whereas no methylation was detected in individuals with normal enzyme activity. Most interestingly, partial DPYD promoter methylation was observed in all DPD deficient individuals not carrying any known inactivating DPYD mutation. These results thus strongly indicated that this epigenetic mechanism might be an important determinant of DPD activity.

Previously [13], we screened the entire coding region of DPYD in 111 cancer patients receiving 5-FU based chemotherapy, including 24 patients with severe toxic side effects (NCI CTCAE grade $\geq 3$ ). However, none of the patients experiencing severe adverse reactions were carriers of a mutation, which has previously been associated with low DPD activity or severe 5-FU toxicity. On the contrary, some of these gene variants, including the IVS14+1G $>$ A splice site mutation, were detected in patients with no or only mild side effects. Since none of the observed grade $\geq 3$ toxicities could be explained by known deleterious DPYD mutations in this study population, we aimed at investigating a potential epigenetic effect in the same patients. In the present study, we therefore assessed the methylation status of the DPYD promoter region in a subsample of this study population, in order to determine the prognostic significance of this epigenetic marker with respect to severe 5-FU toxicity.
The investigated gene region was a 209 base pair fragment of the 5 ' untranslated region of DPYD, the same region as investigated in [12]. This fragment contains $27 \mathrm{CpG}$ sites, eleven of which are located within two sequence elements (shown in Figure 1), which have previously been reported to be of regulatory importance [14]. CpG methylation in this region was assessed in peripheral blood mononuclear cells by bisulfite modification (BSM) of genomic DNA, PCR amplification of the specified gene region using methylation-independent primers, and cloning of amplified fragments. Since partial methylation, as it was observed in the previous study [12], would result in a mixture of methylated and unmethylated DNA copies, the cloning procedure enabled us to separately sequence individual amplified fragments, and thus estimate the proportion of methylated DNA in the sample.

\section{Methods \\ Patients}

A total of 27 patients were investigated, including 17 patients experiencing severe toxicity following fluoropyrimidine treatment, and ten randomly selected control patients who did not develop any or only a mild to moderate toxic reaction (Table 1). All patients suffered from solid malignant tumors and were treated with various chemotherapy regimens including monotherapies with 5FU or capecitabine, and combinations with other cytotoxic drugs (Table 1). None of the analysed patients with severe toxic side effects were carriers of a known deleterious DPYD mutation (Table 1), and all non-synonymous mutations detected in these patients were previously observed at similar frequencies also in patients without severe toxic reaction [15]. Blood samples were collected before or during chemotherapy after getting informed consent from all patients; adverse drug effects during the first and second course of chemotherapy were assessed by detailed chart review, and were classified according to the Common Terminology Criteria for Adverse Events (CTCAE) v3.0 [16]. All toxicities equal to or greater than grade three were considered severe.

\section{Bisulfite modification and PCR amplification of the DPYD promoter region}

Genomic DNA was extracted from EDTA-blood samples using the BioRobot EZ1 (Qiagen) and the EZ1 DNA blood $350 \mu \mathrm{l}$ Kit (Qiagen). Up to $2 \mu \mathrm{g}$ of genomic DNA were subsequently bisulfite-modified (BSM) using the EpiTect Bisulfite Kit (Qiagen) according to the instructions provided by the manufacturer. A 209 bp fragment of the DPYD promoter region was amplified from BSM samples using a GeneAmp 9700 Thermal Cycler (Applied Biosystems) and the same primers as described in [12]. The 25 $\mu \mathrm{l}$ PCR volume contained $1 \mu \mathrm{l}$ of BSM DNA, $1 \mu \mathrm{l}$ of each primer $(10 \mu \mathrm{M}), 1 \mu \mathrm{l}$ of dNTP $(10 \mathrm{mM}$ each), $3 \mu \mathrm{l}$ of $\mathrm{MgCl}_{2}$ solution $(25 \mathrm{mM}), 2.5 \mu \mathrm{l}$ of AmpliTaq Gold Buffer 


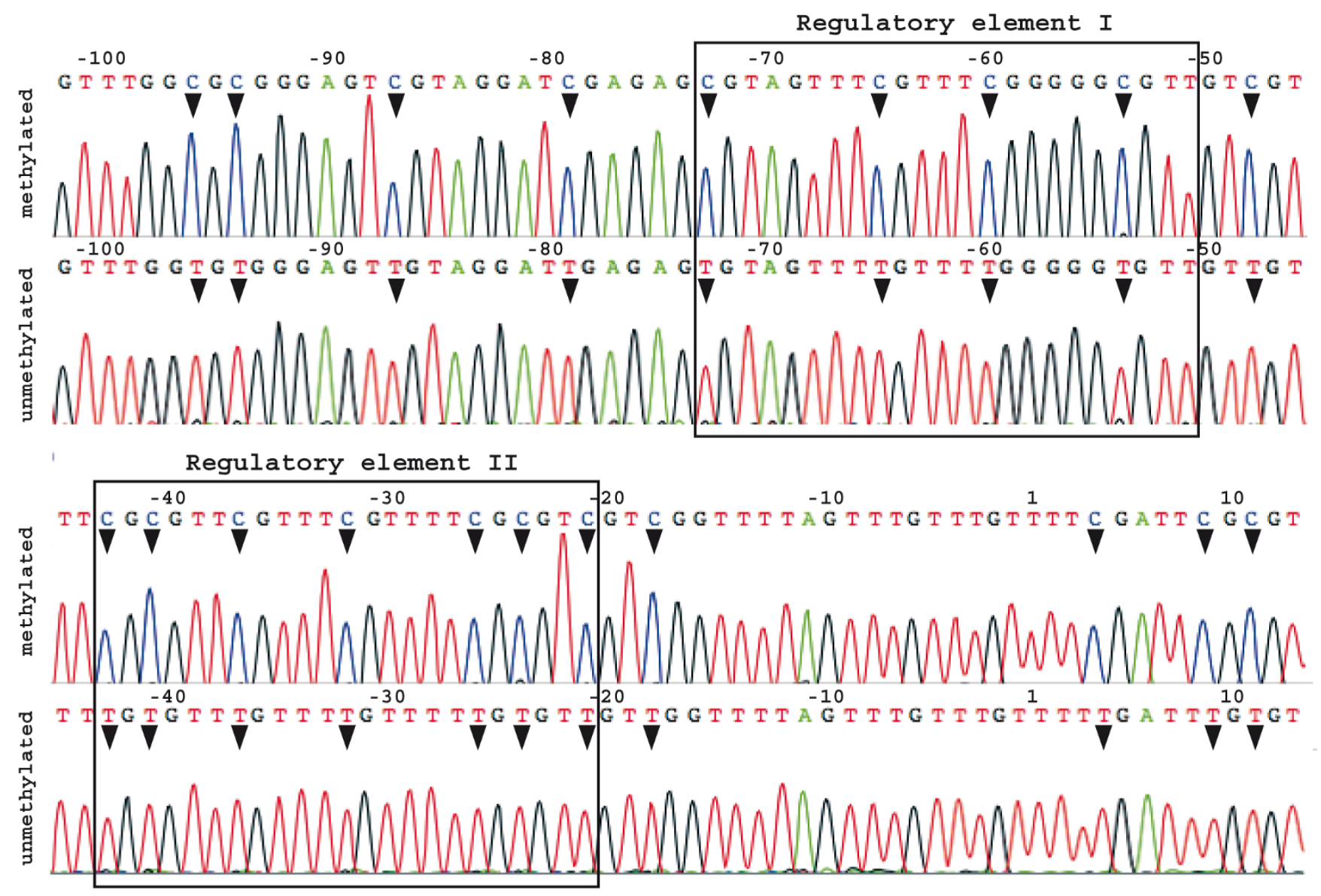

Figure I

BSM induced, methylation-specific sequence differences in the DPYD promoter region. Sequence chromatograms of clone inserts originating from methylated and unmethlyated DNA, obtained in the control experiment using enzymatically methylated DNA. Unmethylated cytosines at CpG sites (indicated with black arrows) are converted to thymines, resulting in a sequence change. The two regulatory elements are shown; numbers indicate the sequence position relative to the transcription start site.

and $0.5 \mu \mathrm{l}$ of AmpliTaq Gold DNA polymerase (Applied Biosystems). The following reaction conditions were used: denaturation at $96^{\circ} \mathrm{C}$ for $10 \mathrm{~min}$, followed by 40 cycles of $50 \mathrm{~s}$ at $96^{\circ} \mathrm{C}, 50 \mathrm{~s}$ at $52^{\circ} \mathrm{C}$, and $1 \mathrm{~min}$ at $72^{\circ} \mathrm{C}$, and a final extension step at $72^{\circ} \mathrm{C}$ for $10 \mathrm{~min}$. PCR products were subsequently re-amplified for cloning using either $1 \mu \mathrm{l}$ of undiluted PCR product (if PCR band was not visible or very weak after first amplification) or $1 \mu \mathrm{l}$ of PCR product diluted 1:100 (if PCR band from first amplification was clearly visible) using touchdown PCR. If amplification with a proofreading polymerase was required for the cloning step (StabyCloning kit), this reamplification step was performed using $0.5 \mu \mathrm{l}$ of Accuprime GC-rich polymerase (Invitrogen) with $5 \mu$ l of the provided $5 \times$ buffer, and $0.5 \mu \mathrm{l}$ of each primer $(10 \mu \mathrm{M})$ in a $25 \mu \mathrm{l}$ reaction volume. Otherwise, the same reaction mix as described above was used. The reaction conditions for the touchdown PCR were the following: an initial denaturation step of $10 \mathrm{~min}$ at $95^{\circ} \mathrm{C}$ was followed by five times two cycles with annealing temperatures lowered gradually from $62^{\circ} \mathrm{C}$ to $54^{\circ} \mathrm{C}$ in steps of $2^{\circ} \mathrm{C}$ with $50 \mathrm{~s}$ at $94^{\circ} \mathrm{C}, 50$ $\mathrm{s}$ at the respective annealing temperature, and $1 \mathrm{~min}$ at $72^{\circ} \mathrm{C}$. This touchdown step was followed by 20 cycles with $50 \mathrm{~s}$ at $94^{\circ} \mathrm{C}, 50 \mathrm{~s}$ at $52^{\circ} \mathrm{C}$, and $1 \mathrm{~min}$ at $72^{\circ} \mathrm{C}$, and a final extension step of $10 \mathrm{~min}$ at $72^{\circ} \mathrm{C}$.

\section{Cloning and sequence analysis}

After purification using the QIAquick PCR Purification Kit (Qiagen), PCR products were cloned using the StabyCloning kit (Eurogentec) or the QIAGEN PCR cloning kit (Qiagen) according to the instructions given by the manufacturer. For each sample analysed, a total of 19 to 30 different colonies (Table 1) containing the correct insert were amplified using AmpliTaq Gold DNA 
Table I: Clinical data of investigated patients, DPYD genotype and number of clones sequenced per patient.

\begin{tabular}{|c|c|c|c|c|c|c|c|c|c|c|}
\hline & \multirow[b]{2}{*}{ Sex } & \multirow[b]{2}{*}{ Age } & \multirow[b]{2}{*}{ Tumor } & \multirow[b]{2}{*}{ Regimen } & \multicolumn{3}{|c|}{ Toxicity grade } & \multirow[b]{2}{*}{$\begin{array}{c}\text { DPYD genotype } \\
\text { (coding region/splice sites) }\end{array}$} & \multicolumn{2}{|c|}{$\mathrm{N}$ clones } \\
\hline & & & & & hematologic & gastrointestinal & dermatologic & & Total & Methylated \\
\hline \multicolumn{11}{|c|}{ Patients with severe 5-FU related toxicity } \\
\hline I & $\mathrm{m}$ & 53 & Gastric & 5FU-FA & I & 3 & 0 & - & 21 & 0 \\
\hline 2 & $f$ & 70 & Breast & CAPE & 0 & 3 & 0 & $\begin{array}{c}\text { c.85T>C, C29R; c.496A>G, } \\
\text { MI66V }\end{array}$ & 20 & 0 \\
\hline 3 & $f$ & 55 & Gastric & CAPE-P & 3 & 0 & 0 & c. 160 IG>A, S534N & 21 & 0 \\
\hline 4 & $\mathrm{~m}$ & 74 & Colon & 5FU-FA-P & 4 & 4 & 0 & - & 20 & 0 \\
\hline 5 & $f$ & 53 & Colon & 5FU-FA-P & 3 & 1 & 0 & c. $496 \mathrm{~A}>\mathrm{G}, \mathrm{MI} 66 \mathrm{~V}$ & 21 & 0 \\
\hline 6 & $\mathrm{~m}$ & 66 & Tonsil & 5FU-P & 2 & 3 & 3 & c.85T>C, C29R; I236G>A, E4I2E & 20 & 0 \\
\hline 7 & $\mathrm{~m}$ & 53 & Oesophagus & 5FU-P & 4 & 4 & 0 & - & 20 & 0 \\
\hline 8 & $f$ & 54 & Breast & E-5FU-C & 3 & I & 0 & $1627 \mathrm{~A}>\mathrm{G}, 1543 \mathrm{~V}$ & 21 & 0 \\
\hline 9 & $f$ & 65 & Gastric & E-5FU-P & 3 & I & 2 & - & 22 & 0 \\
\hline 10 & $\mathrm{~m}$ & 79 & Oesophagus & $5 F U-P$ & 2 & 3 & 0 & $\begin{array}{c}\text { c.85T>C, C29R; c. I236G }>\text { A, } \\
\text { E4I2E }\end{array}$ & 20 & 0 \\
\hline 11 & $f$ & 67 & Rectum & 5FU-P & 4 & 4 & 0 & c. $496 \mathrm{~A}>\mathrm{G}, \mathrm{M} 166 \mathrm{~V}$ & 22 & 0 \\
\hline 12 & $f$ & 57 & Gastric & E-5FU-P & 3 & 1 & 0 & $\begin{array}{l}\text { c.85T>C, C29R; c. I236G>A, } \\
\text { E4I 2E; c. I627A >G, I543V }\end{array}$ & 20 & 0 \\
\hline 13 & $\mathrm{~m}$ & 57 & Rectum & $5 F U$ & 3 & 0 & 0 & $1896 \mathrm{~T}>\mathrm{C}, \mathrm{F} 632 \mathrm{~F}$ & 21 & 0 \\
\hline 14 & $\mathrm{~m}$ & 67 & unknown ${ }^{\mathrm{a}}$ & 5FU-IRI & 3 & 0 & 0 & $\begin{array}{c}\text { c.85T>C, C29R; c. 1627A>G, } \\
\text { I543V }\end{array}$ & 24 & 0 \\
\hline 15 & $f$ & 50 & Rectum & 5FU-FA-P & I & 3 & 0 & $c .85 T>C, C 29 R$ & 25 & 0 \\
\hline 16 & $\mathrm{~m}$ & 75 & Gastric & $5 F U$ & 2 & 3 & 0 & - & 21 & 0 \\
\hline 17 & $f$ & 47 & Breast & CAPE & 1 & I & 3 & $\begin{aligned} \text { c.85T>C, } & \text { C29R; c. } 496 \mathrm{~A}>\mathrm{G}, \\
& \text { M166V }\end{aligned}$ & 30 & 0 \\
\hline \multicolumn{11}{|c|}{ Control patients } \\
\hline 18 & $f$ & 72 & Rectum & $5 F U$ & I & I & 0 & - & 20 & 0 \\
\hline 19 & $f$ & 54 & Gastric & 5FU-FA-P & 2 & i & 0 & c. $1679 \mathrm{~T}>\mathrm{G}, 1560 \mathrm{~S}$ & 21 & 0 \\
\hline 20 & $\mathrm{~m}$ & 59 & Pancreas & 5FU-FA-P & 0 & I & 0 & 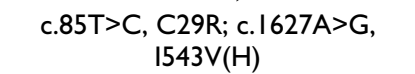 & 20 & 0 \\
\hline 21 & $\mathrm{~m}$ & 62 & Colon & 5FU-FA-P & 0 & I & 0 & $\begin{array}{c}\text { c. } 85 \mathrm{~T}>\mathrm{C}, \mathrm{C} 29 \mathrm{R}(\mathrm{H}) ; \mathrm{c} .496 \mathrm{~A}>\mathrm{G} \\
\mathrm{MI} 66 \mathrm{~V}, \text { c. } 1236 \mathrm{G}>\mathrm{A}, \mathrm{E} 4 \mathrm{I} 2 \mathrm{E}\end{array}$ & 19 & 0 \\
\hline 22 & $f$ & 64 & Colon & 5FU-FA & 0 & 0 & 0 & $\begin{array}{c}\text { c.85T>C, C29R; c. 1627A>G, } \\
1543 \mathrm{~V}\end{array}$ & 20 & 0 \\
\hline 23 & $\mathrm{~m}$ & 63 & Oesophagus & 5FU-P & I & 0 & 0 & - & 20 & 0 \\
\hline 24 & $f$ & 69 & Colon & 5FU-FA & 0 & 1 & 0 & $\begin{array}{c}\text { c.85T>C, C29R (H); c.496A>G, } \\
\text { MI66V; c.2194G>A, V732I }\end{array}$ & 20 & 0 \\
\hline 25 & $\mathrm{~m}$ & 59 & Gastric & 5FU-FA & 1 & I & 0 & $\begin{array}{c}\text { c.85T>C, C29R; c. I627A >G, } \\
\text { I543V; I896T>C, F632F }\end{array}$ & 21 & 0 \\
\hline 26 & $\mathrm{~m}$ & 59 & Colon & 5FU-FA-P & 1 & I & 0 & $\begin{array}{c}\text { c.85T>C, C29R (H); c.496A>G } \\
\text { MI66V; c.1627A>G, I543V }\end{array}$ & 20 & 0 \\
\hline 27 & $\mathrm{~m}$ & 62 & Gastric & E-CAPE-P & 2 & 1 & 2 & $\begin{array}{c}\text { c.85T>C, C29R (H); c.496A>G } \\
\text { MI66V; c. I236G>A, E4I IE } \\
\text { c. } 1627 \mathrm{~A}>\mathrm{G}, 1543 \mathrm{~V}\end{array}$ & 30 & 0 \\
\hline
\end{tabular}

Abbreviations: FA, folinic acid; CAPE, capecitabine; P, platinum compound; E, epirubicin; C, cyclophosphamide; $\mathrm{H}$, homozygous carrier a adenocarcinoma of unknown origin

polymerase (Applied Biosystems) in the same reaction mix as described above and the primers provided by the manufacturer for the Staby Cloning kit, or T7 and M13 for the QIAGEN PCR cloning kit, respectively. Amplified inserts were subsequently sequenced using the same primers, the Big Dye Terminator v3.1 Cycle Sequencing Kit (Applied Biosystems) and an ABI Prism 3130xl Genetic Analyzer (Applied Biosystems). The obtained sequences were analysed for methylation-specific, bisulfite-induced sequence changes using the software Sequencher v.4.7 (Gene Codes Corporation).

\section{Enzymatic methylation of genomic DNA}

To exclude a potential amplification bias during PCR amplification and to establish the detection limit of the cloning procedure, a control experiment was conducted using various amounts of enzymatically methylated genomic DNA. For enzymatic methylation, genomic DNA 
from two randomly selected patients was methylated using CpG Methylase M.SssI (New England BioLabs). Approximately $1 \mu \mathrm{g}$ of DNA was incubated for two hours at $37^{\circ} \mathrm{C}$ with $1 \mu \mathrm{l}$ of SssI, $5 \mu \mathrm{l}$ of NEBuffer 2 (New England BioLabs) and $5 \mu \mathrm{l}$ of S-adenosylmethionine $(1.6 \mathrm{mM})$ in a reaction volume of $50 \mu \mathrm{l}$, followed by an inactivation step of $20 \mathrm{~min}$ at $65^{\circ} \mathrm{C}$. Reactions were subsequently purified using standard phenol-chloroform purification, followed by ethanol precipitation. The precipitated DNA was resolved in $15 \mu \mathrm{l}$ of the same elution buffer as used for the isolation of genomic DNA from patient samples. The two methylated DNA samples were subsequently pooled and mixed with BSM genomic DNA from an unmethylated patient sample to contain $10 \%, 20 \%, 50 \%$ and $100 \%$ methlyated BSM DNA, and subjected to the same procedure as described for the patient samples.

\section{Results and discussion}

No evidence of DPYD promoter methylation was observed in any of the 17 investigated patients experiencing severe 5-FU toxicity. Also in the ten control patients, no indication for DPYD promoter methylation was found (Table 1). More specifically, in all of the 19 to 30 cloned fragments analysed per patient, a majority (mean: 98\%; range: $81 \%-100 \%$ ) of the 27 CpG sites showed BSMinduced conversions of cytosines to thymines, indicative of unmethlyated cytosines (as shown in Figure 1). On the other hand, increasing numbers of clones containing methylated gene copies, indicated by the preservation of cytosines in the sequence (Figure 1), were detected in the control experiment, according to the amount of enzymatically methylated DNA added. In the fragments considered as showing methylation, on average, $90 \%$ of the CpG sites were methylated (range: $41-100 \%$ ). In the sample containing $100 \%$ methylated DNA, 18 out of 22 analysed clones contained methylation-specific sequences (82\%), indicating an efficiency of the enzymatic methylation of about $80 \%$. One methylated gene copy was detected also in the sample containing only $10 \%$ methylated BSM DNA (one out of 20 analysed clones). In the samples containing 20\% and 50\% methylated DNA, intermediate numbers of methylated clones were observed (five out of 21 and five out of 20 clones, respectively). Therefore, we concluded that as little as $10 \%$ methylation of the DPYD promoter region should be detectable using the abovedescribed procedure. Also, the results of this control experiment showed no indication for an amplification bias towards unmethylated gene copies.

The occurrence of severe 5-FU related toxicity in the 17 investigated patients was thus not explained by an epigenetic regulation of the DPYD promoter region. Our findings are in agreement with an other recent study, where no evidence for DPYD promoter methylation was detected in 28 patients with grade 4 toxicity following 5 -FU adminis- tration [15]. To our knowledge, only the study mentioned above and our own have investigated the predictive potential of DPYD promoter methylation in larger samples of 5-FU treated patients, and both studies did not detect any evidence for such an epigenetic downregulation of DPD. However, although no study so far was able to confirm the initial findings by [12], which were based on a very small sample size, various studies nevertheless suggest epigenetic factors as an alternative explanation for the occurrence of severe 5-FU toxicity where no other molecular basis was found in DPYD [17-19].

Therefore, it is important to recognise that our results and those by [15] strongly indicate that DPYD promoter methylation is, if at all, only of minor importance as a predictive factor for severe toxic side effects in 5-FU based chemotherapy. The molecular basis of severe 5-FU toxicity can thus currently not be attributed to known genetic or epigenetic factors in the DPD gene for a majority of the observed cases in this and other studies $[15,17,20]$. Whereas it can not be excluded that other, yet unknown genetic or epigenetic factors resulting in a reduced DPD activity may be of value for the prediction of 5-FU toxicity, also various polymorphisms in genes other than DPYD have recently been shown to be correlated with the occurrence of severe adverse side effects to 5-FU [21-23]. A promising approach for future investigations could therefore be to expand the focus from investigating isolated genes like DPYD to a more comprehensive view of taking into account genetic variation in the entire biological pathway [24]. Hopefully, such combinatory approaches will finally lead to results, which are both reproducible and translatable into the clinic.

\section{Conclusion}

Our results indicate that DYPD promoter hypermethylation is not of major importance as a prognostic factor for severe toxicity in 5-FU based chemotherapy.

\section{Competing interests}

The authors declare that they have no competing interests.

\section{Authors' contributions}

CRL, UA and SA conceived the study. UA carried out the experiments and drafted the manuscript. SF participated in the collection of patient samples and information on 5FU related toxicities. All authors contributed to the writing of the manuscript.

\section{Acknowledgements}

The authors would like to thank Karin Schnyder and Gisela Andrey-Zürcher for their contributions to the experimental part of this study and Gabriela Mäder-Heinemann for helpful discussions. Financial support for this work was provided by a research grant from the Swiss National Science Foundation (3I-I I 9839) to CRL and SA. 


\section{References}

I. Ezzeldin H, Diasio R: Dihydropyrimidine dehydrogenase deficiency, a pharmacogenetic syndrome associated with potentially life-threatening toxicity following 5-fluorouracil administration. Clin Colorectal Cancer 2004, 4: |8|-189.

2. Levy E, Piedbois P, Buyse M, Pignon JP, Rougier P, Ryan L, Hansen R, Zee B, Weinerman B, Pater J, et al.: Toxicity of fluorouracil in patients with advanced colorectal cancer: effect of administration schedule and prognostic factors. Meta-Analysis Group In Cancer. J Clin Oncol 1998, 16:3537-354I.

3. Milano G, McLeod HL: Can dihydropyrimidine dehydrogenase impact 5-fluorouracil-based treatment? Eur J Cancer 2000, 36:37-42.

4. Etienne M, Lagrange J, Dassonville O, Fleming R, Thyss A, Renée N, Schneider M, Demard F, Milano G: Population study of dihydropyrimidine dehydrogenase in cancer patients. J Clin Oncol 1994, I 2:2248-2253.

5. Van Kuilenburg A: Dihydropyrimidine dehydrogenase and the efficacy and toxicity of 5-fluorouracil. Eur J Cancer 2004, 40:939-950.

6. Mattison L, Soong R, Diasio R: Implications of dihydropyrimidine dehydrogenase on 5-fluorouracil pharmacogenetics and pharmacogenomics. Pharmacogenomics 2002, 3:485-492.

7. Lazar A, Mau-Holzmann UA, Kolb H, Reichenmiller HE, Riess $O$, Schömig E: Multiple organ failure due to 5-fluorouracil chemotherapy in a patient with a rare dihydropyrimidine dehydrogenase gene variant. Onkologie 2004, 27:559-562.

8. Raida M, Schwabe W, Häusler P, Van Kuilenburg A, Van Gennip A, Behnke D, Höffken K: Prevalence of a common point mutation in the dihydropyrimidine dehydrogenase (DPD) gene within the 5 '-splice donor site of intron 14 in patients with severe 5 fluorouracil (5-FU)-related toxicity compared with controls. Clin Cancer Res 200I, 7:2832-2839.

9. Seck K, Riemer S, Kates R, Ullrich T, Lutz V, Harbeck N, Schmitt M, Kiechle M, Diasio R, Gross E: Analysis of the DPYD gene implicated in 5-fluorouracil catabolism in a cohort of Caucasian individuals. Clin Cancer Res 2005, I I:5886-5892.

10. Wei X, McLeod HL, McMurrough J, Gonzalez FJ, Fernandez-Salguero $\mathrm{P}$ : Molecular basis of the human dihydropyrimidine dehydrogenase deficiency and 5-fluorouracil toxicity. J Clin Invest 1996, 98:610-615.

II. Vreken P, Van Kuilenburg AB, Meinsma R, Smit GP, Bakker HD, De Abreu $\mathrm{RA}$, van Gennip $\mathrm{AH}$ : A point mutation in an invariant splice donor site leads to exon skipping in two unrelated Dutch patients with dihydropyrimidine dehydrogenase deficiency. J Inherit Metab Dis 1996, I 9:645-654.

12. Ezzeldin H, Lee A, Mattison L, Diasio R: Methylation of the DPYD promoter: an alternative mechanism for dihydropyrimidine dehydrogenase deficiency in cancer patients. Clin Cancer Res 2005, I I:8699-8705

13. Amstutz U, Farese S, Aebi S, Largiadèr CR: Dihydropyrimidine dehydrogenase gene variation and severe 5-fluorouracil toxicity: A haplotype assessment. in press.

14. Shestopal S, Johnson M, Diasio R: Molecular cloning and characterization of the human dihydropyrimidine dehydrogenase promoter. Biochim Biophys Acta 2000, I 494: I62-169.

15. Schwab M, Zanger UM, Marx C, Schaeffeler E, Klein K, Dippon J, Kerb R, Blievernicht J, Fischer J, Hofmann U, et al.: Role of Genetic and Nongenetic Factors for Fluorouracil Treatment-Related Severe Toxicity: A Prospective Clinical Trial by the German 5-FU Toxicity Study Group. J Clin Oncol 2008, 26:2131-2138.

16. Common Terminology Criteria for Adverse Events v3.0 [http://ctep.cancer.gov/reporting/ctc v30.html]

17. Magné N, Etienne-Grimaldi MC, Cals L, Renée N, Formento JL, Francoual M, Milano G: Dihydropyrimidine dehydrogenase activity and the IVSI4+ I G>A mutation in patients developing 5FUrelated toxicity. Br J Clin Pharmacol 2007, 64:237-240.

18. Morel A, Boisdron-Celle M, Fey L, Soulie P, Craipeau MC, Traore S, Gamelin E: Clinical relevance of different dihydropyrimidine dehydrogenase gene single nucleotide polymorphisms on 5fluorouracil tolerance. Mol Cancer Ther 2006, 5:2895-2904.

19. Ezzeldin HH, Diasio RB: Predicting fluorouracil toxicity: can we finally do it? J Clin Oncol 2008, 26:2080-2082.

20. Collie-Duguid ESR, Etienne MC, Milano G, McLeod HL: Known variant DPYD alleles do not explain DPD deficiency in cancer patients. Pharmacogenetics 2000, 10:217-223.
21. Ichikawa W, Takahashi T, Suto K, Sasaki Y, Hirayama R: Orotate phosphoribosyltransferase gene polymorphism predicts toxicity in patients treated with bolus 5 -fluorouracil regimen. Clin Cancer Res 2006, I 2:3928-3934.

22. Lecomte T, Ferraz J, Zinzindohoué F, Loriot M, Tregouet D, Landi B, Berger A, Cugnenc P, Jian R, Beaune P, Laurent-Puig P: Thymidylate synthase gene polymorphism predicts toxicity in colorectal cancer patients receiving 5-fluorouracil-based chemotherapy. Clin Cancer Res 2004, I 0:5880-5888.

23. Etienne M, llc K, Formento J, Laurent-Puig P, Formento P, Cheradame $S$, Fischel J, Milano G: Thymidylate synthase and methylenetetrahydrofolate reductase gene polymorphisms: relationships with 5-fluorouracil sensitivity. Br J Cancer 2004, 90:526-534.

24. Ulrich C, Robien K, McLeod H: Cancer pharmacogenetics: polymorphisms, pathways and beyond. Nat Rev Cancer 2003, 3:912-920.
Publish with Biomed Central and every scientist can read your work free of charge

"BioMed Central will be the most significant development for disseminating the results of biomedical research in our lifetime. "

Sir Paul Nurse, Cancer Research UK

Your research papers will be:

- available free of charge to the entire biomedical community

- peer reviewed and published immediately upon acceptance

- cited in PubMed and archived on PubMed Central

- yours - you keep the copyright

Submit your manuscript here:

http://www.biomedcentral.com/info/publishing_adv.asp
BioMedcentral 